\title{
DETERMINE THE IMPORTANT OF KIDNEY TRANSPLANTATION ITEMS IN SELECTED COUNTRIES AND IRAN (APPLICATION REGISTRY)
}

\author{
Type of article: conference abstract
}

Majid Jangi1, Mahmoud Tara*2, Kolsoum Deldar1

1: PhD candidate of Medical Informatics, Department of Medical Informatics, School of Medicine, Mashhad University of Medical Sciences, Mashhad, Iran, Email: Jangim922@mums.ac.ir

2: Mahmoud Tara (corresponding author), Associate Professor, Medical Informatics, Department of Medical Informatics, School of Medicine, Mashhad University of Medical Sciences, Mashhad, Iran. Email: Taram@mums.ac.ir

\begin{abstract}
Introduction: In many cases a kidney transplant is effective treatment for advanced chronic kidney disease and ESRD patients. There are multiple items to identify candidates for a kidney transplant. So one of the problems, considerable differences in factors, because of the vastness and the variety of factors affecting them. The purpose of this study is to provide a comparative analysis of kidney transplantation items in selected countries and Iran in order to choose the most important items that will be used in Iran.

Methods: The study was carried out in 2015 using a comparative review method in United States, Australia, Croatia and Iran. The countries have the largest number of kidney transplants on their continent in 2014. Items in two categories (Candidate's items and Donor's items) was gathered from last version guidelines and execute Delphi rounds and focus group(feasibility) to choose the important criteria in 3 Iran's medical centers. Data analyzed by Excel 2015.

Results: Total items of candidate was twenty that five items, including "duration of dialysis", "blood type", "previous transplant history", "age" and "HLA" were considered as items affecting transplant in all three countries. Iran just included two items (duration of dialysis and blood type). After Delphi rounds and accessibility study, sixteen items were remain to gathering in Iran.

Total items of donor was thirteen that three items, including "blood type", "age" and "HLA" were considered as items affecting transplant in all three countries. Iran just included 2 items (hepatitis and blood type). After Delphi rounds and feasibility study, 11 items were remain to gathering in Iran. Croatia that adherence Euro guideline in kidney transplantation had maximum candidate's items and United states has maximum donors items that involving in kidney transplantation

Conclusion: Kidney transplantation items determine the amount of readiness kidney transplant candidates and the quality of the kidney donor. In Iran this items did not intended to be the comparison candidates and just "duration of dialysis" was criterion. While in America, Europe and Australia the readiness of candidate and the quality of the kidney donor is based on the items scoring and matching. One of the deleted items as a result of feasibility study in Iran was the HLA typing test. Due to the long time and high cost, there is no possibility of collecting it.projected is if Iran involved items in queues waiting for a transplant candidates, they will receive graft survival rate better than before.
\end{abstract}

KEYWORDS: Kidney, Application Registry, Transplantation

\section{Declaration of conflicts}

This abstract is selected from the First International Congress of Diseases and Health Outcomes Registry and First National Congress of Medical Informatics, 14-17 February 2017, Mashhad, Iran 
Medical Technologies Journal, Volume: 1, Issue: 4, October-December 2017, Pages:76-136. Doi : https://doi.org/10.26415/2572-004X-vol1iss4

\section{Authors' biography}

No biography.

\section{References}

No references. 